Check for updates

Cite this: J. Mater. Chem. C, 2022, 10,805

Received 6th May 2021 Accepted 22nd November 2021

DOI: $10.1039 / d 1 t c 02105 b$

rsc.li/materials-c

\title{
Magnetic cellulose: does extending cellulose versatility with magnetic functionality facilitate its use in devices?
}

\begin{abstract}
Tiina Nypelö (D) ab
Magnetism is certainly one of the most intriguing properties of materials. It provides a means for manipulating macroscopic and microscopic positioning and alignment of materials and is a characteristic that is essential for the creation of numerous devices and appliances. Cellulose is a renewable resource that encompasses a diverse portfolio of material hierarchies: the cellulose molecule, molecular clusters, fibrils, fibers, films, and wood products. Cellulose is exploited in materials due to its impressive intrinsic properties of non-toxicity, low density, and low cost as well as due to the extraordinary material properties of thermal stability and strength. However, many devices operate on electrical or magnetic signals, a functionality that cellulose lacks. To exploit cellulose in such applications, cellulose is often modified by ferromagnetic particles. Ferromagnetic cellulose fibers are not only demonstrated for separation of biomolecules and environmental accumulations but also in electrical textiles, loudspeakers, magnetic shielding, and optical and medical devices. This review focuses on presenting the current selection of methods for rendering cellulose magnetic; its demonstrated use in devices; and an outlook on the challenges, application, and gaps in knowledge of creating the requisite materials.
\end{abstract}

\section{Introduction}

${ }^{a}$ Chalmers University of Technology, 41296 Gothenburg, Sweden.

E-mail: tiina.nypelo@chalmers.se

${ }^{b}$ Wallenberg Wood Science Center, Chalmers University of Technology,

41296 Gothenburg, Sweden

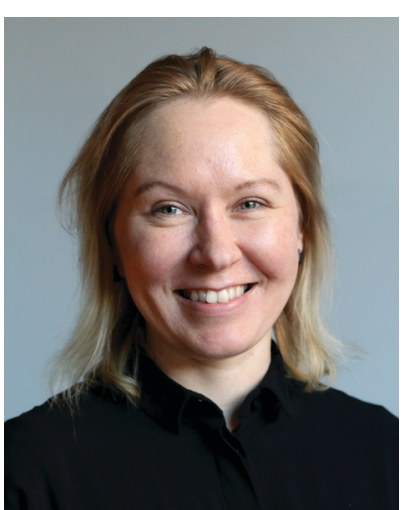

Tiina Nypelö
Tiina Nypelö received doctorate in forest products surface chemistry from Aalto University, Finland 2012. She stayed for postdoctoral research periods in North Carolina State University, USA, and in University of Natural Resources and Life Sciences in Vienna, Austria. From 2017 she has been at Chalmers University of Technology and at Wallenberg Wood Science Center, and is Associate professor working on the topic of bio-based materials. Her research interests involve cellulose, hemicelluloses and lignins with emphasis on surface, interface, and intermolecular interactions.
Cellulose is a marvelous material available in nature; it comes in various formats, either natural or human-made. Much effort has been directed to functionalize cellulose to enable its use in active materials and applications that require a prompt stimuli-response. Cellulose is a material with much to offer to materials science. Cellulose fibers are a non-toxic, inexpensive (e.g., bleached hardwood kraft pulp price approximately 980 USD per metric tonnes $\left.{ }^{1}\right)$ and abundant (e.g., 190 million tons of wood pulp produced annually ${ }^{2}$ ) material for paper, textiles, and packaging, to name just a few fields of use. In addition to the "dry" forms, its hygroscopic nature makes nanosized cellulose an appealing material for hydrogels potential for medical uses. Cellulose does not melt until the onset of degradation at $240{ }^{\circ} \mathrm{C},{ }^{3}$ and cellulose particles and fibers are frequently used to reinforce polymer matrixes ${ }^{4-7}$ that benefit from its high elastic modulus and aspect ratio. In engineered materials, cellulose is often used as a substrate and carrier material and has also been demonstrated as a carrier for magnetic moieties and magnetic materials.

The aim of this review is to present the aspects related to the intrinsic magnetic properties of cellulose and the synthesis of (ferro) magnetic cellulose hybrids, their properties, and applications. The outlook provides a discussion on the limitations 
of current preparation methods and the uses of magnetic cellulose.

Both cellulose that exhibits the backbone structure of $\beta-1,4-$ linked anhydroglucose units (AGU) and hydroxyl functionality as well as modifications that introduce a functionality but preserve the cellulose hierarchy are included here. This review focuses on cellulose from forest resources, its various hierarchical structures, and its use in devices that require magnetic functionality. Forest-based cellulose materials are available from the pulp and paper sector and may be considered abundant and currently a more widely available commodity than, for example, cellulose synthetized by bacteria. Bacterial cellulosemagnetic materials have been reviewed by Sriplai et al. ${ }^{8}$ and Hu et al. ${ }^{9}$ but these are excluded from this review.

In demonstrations where cellulose has been carbonized, separation and enzyme immobilization with magnetic cellulose ${ }^{10}$ and magnetic acid catalysis for cellulose hydrolysis are largely excluded. The focus is on the literature published between 2010 and 2021 .

\section{Characteristics of supramolecular cellulose}

The continuous motivation toward fundamentals and developing cellulose-based materials may be influenced by two aspects. First, cellulose is a polysaccharide with a high degree of polymerization. It consists of cyclic monosaccharides, linked via glycosidic bonds, thereby resulting in a linear macromolecule with backbone stiffness that, along with intrachain hydrogen bonding (Fig. 1), contributes to making cellulose dissolution behavior complex and intriguing. Second, the cellulose chains form structures beyond a single polymer chain and the resulting supramolecular structures

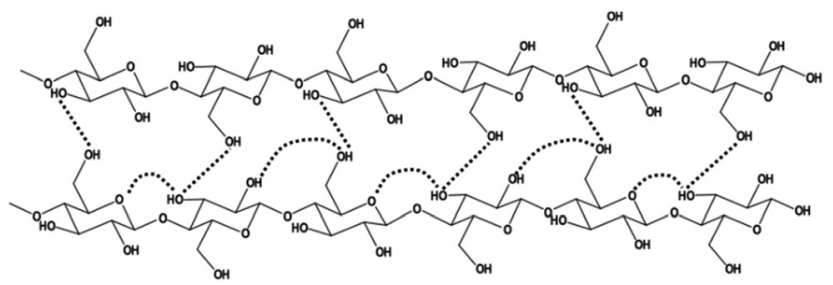

Fig. 1 Structure of cellulose and inter and intrachain hydrogen bonding (dashed line). provide an immense number of structural building blocks for purposes related to chemistry, physics, and materials science.

\section{Hierarchical structure of cellulose}

Every other AGU is flipped over and glycosidic bonded (Fig. 1) forming a high molecular weight macromolecule that is at the lowest level of material hierarchy of cellulose considered here (Table 1). In plants, these cellulose chains are synthetized into fibrils, which are the structural units that constitute the cell wall of plant fiber. The fibers are often the targeted material from plant tissue for engineering purposes. The liberation of cellulose from wood via pulping ${ }^{11}$ is a voluminous industrial process, which provides fibers for paper, textiles, and packaging materials. Exposing the wood fibers into further chemical and mechanical treatments liberates the fibers and fibrils into nanofibers and particles. These materials are called nanocelluloses. The main engineering grades of nanocelluloses are cellulose nanofibers (CNFs) and cellulose nanocrystals (CNCs) (Fig. 2). CNFs are characterized by longer length and lower crystallinity than CNCs, which are rod-like particles produced typically via acid hydrolysis (Table 1). CNFs are excellent filmforming materials with good barrier properties. ${ }^{12}$ Furthermore, CNCs are a remarkable cellulose grade of lyotropic colloidal nanoparticles ${ }^{13}$ and have tremendous potential to revolutionize nanotechnology. ${ }^{14-16}$ CNCs self-assemble into a cholesteric liquid crystal order, in which they form a chiral organization. A nematic liquid crystal order where CNCs orient almost unidirectionally can be facilitated by applying shear force to a suspension. ${ }^{15}$

Cellulose can be dissolved into solvents such as $N$-methylmorpholine- $N$-oxide ${ }^{17}$ and ionic liquids ${ }^{18}$ that enable the formation of films and fibers into solutions. Such regenerated fibers are the basis of modern textile manufacturing. They have greater homogeneity compared to native fibers and can be spun in a continuous process into filaments. The filaments are further processed into staple fibers and threads for garment and technical textiles. ${ }^{17}$ Indeed, cellulose is a family of materials that spans from molecular to macroscopic hierarchies (Table 1).

\section{The magnetic properties of materials}

Magnetism is caused by the movement and spin of electrons. The number of unpaired electrons and the size of the atom

Table 1 Cellulose hierarchies available from wood for engineering, for example, magnetic cellulose materials

\begin{tabular}{|c|c|c|}
\hline Structure & Hierarchy & Size \\
\hline Cellulose macromolecule ${ }^{19}$ & Molecular & $\AA$ \\
\hline Cellulose nanocrystals (CNCs), also called whiskers ${ }^{13,20,21}$ & Molecular to nano & $\begin{array}{l}d 3-5 \mathrm{~nm} \\
L 100-300 \mathrm{~nm}\end{array}$ \\
\hline Cellulose nanofibers (CNFs) ${ }^{22-25}$ & Molecular to micro & $\begin{array}{l}d 7-170 \mathrm{~nm} \\
L \text { few } \mu \mathrm{ms}\end{array}$ \\
\hline Native fibers (macrofibres) ${ }^{26,27}$ & Molecular to macro & $\begin{array}{l}d 20-35 \mu \mathrm{m} \\
L 1-3 \mathrm{~mm}\end{array}$ \\
\hline Regenerated cellulose fibers and filaments (macrofibres) ${ }^{17,28}$ & Molecular to macro & $d$ tens of $\mu \mathrm{m}$ \\
\hline Papers, membranes, textiles & Molecular to macro & Diverse \\
\hline
\end{tabular}



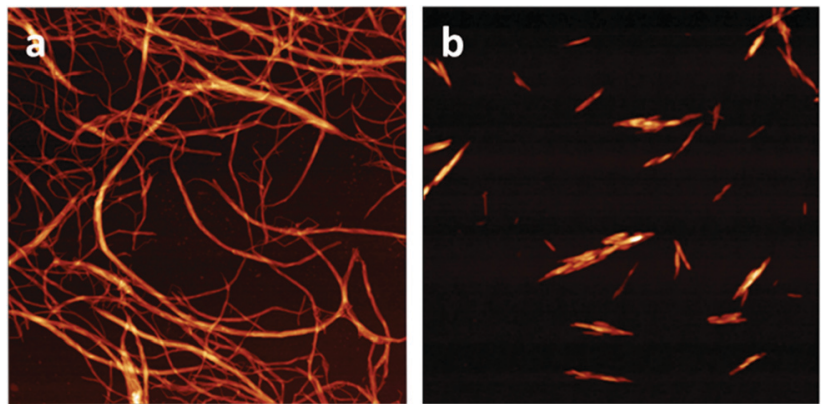

Fig. 2 Atomic force microscopy visualization of cellulose nanofibers (a) and cellulose nanocrystals (b). The frame size is $3 \times 3 \mu \mathrm{m}$.

define the magnitude of magnetism. The magnetic character is divided into ferromagnetic, ferrimagnetic, antiferromagnetic, paramagnetic, superparamagnetic, and diamagnetic behavior (some of which are illustrated in Fig. 3). Ferromagnetic materials have the highest magnetic susceptibility, as all the molecular magnetic dipoles permanently align in the same direction (even without an external magnetic field, $H, H=0$ ). In antiferromagnetic (and ferrimagnetic) materials, the dipoles align into opposite directions, thereby reducing magnetic susceptibility. Paramagnetic atoms and molecules have a magnetic moment and are weakly affected and attracted by a magnet; however, they cannot form a permanent magnet. Furthermore, superparamagnetism is a property of small particles, where magnetization can flip direction under the influence of temperature. Diamagnetic materials do not have a magnetic moment, but the magnetic field creates more induced magnetic fields in the opposite direction of the main field.

\section{Ferromagnetism}

The most familiar form of magnetic materials are ferromagnetic materials that form permanent magnets. Iron (Fe), cobalt (Co), and nickel (Ni) are the main ferromagnetic substances and 3d-block elements in the fourth period. Their electron configuration has five $3 \mathrm{~d}$ orbitals, each of which can include two electrons. Moreover, according to Hund's rule, orbitals of similar energy levels are occupied first with parallel spins rather than paired ones (Fig. 4). For example, for iron $\left(3 d^{6}\right)$, the ground state consists of one fully occupied d-orbital (with paired electrons) and four unpaired (Fig. 4) ones. Iron, cobalt, and nickel with their 4, 3, and 2 unpaired electrons, respectively, are ferromagnetic materials.

Furthermore, paramagnetism also originates from unpaired electrons. However, the magnetism is not maintained when the magnetic field is removed. Diamagnetic materials have only paired electrons and in a magnetic field, align in the direction opposite to that of the field. Magnetic materials in engineering are typically alloys of iron, aluminum, nickel, cobalt, and rare earth elements, such as samarium, dysprosium, and neodymium. Iron can form magnetite $\left(\mathrm{Fe}_{3} \mathrm{O}_{4}\right)$, hematite/maghemite $\left(\mathrm{Fe}_{2} \mathrm{O}_{3}\right)$, limonite $\left(\mathrm{Fe}_{2} \mathrm{O}_{3} \times \mathrm{H}_{2} \mathrm{O}\right)$, and siderite $\left(\mathrm{FeCO}_{3}\right)$ from which magnetite $\left(\mathrm{Fe}_{3} \mathrm{O}_{4}\right)$ and maghemite $\left(\gamma-\mathrm{Fe}_{2} \mathrm{O}_{3}\right)$ are common in nanoparticle forms.
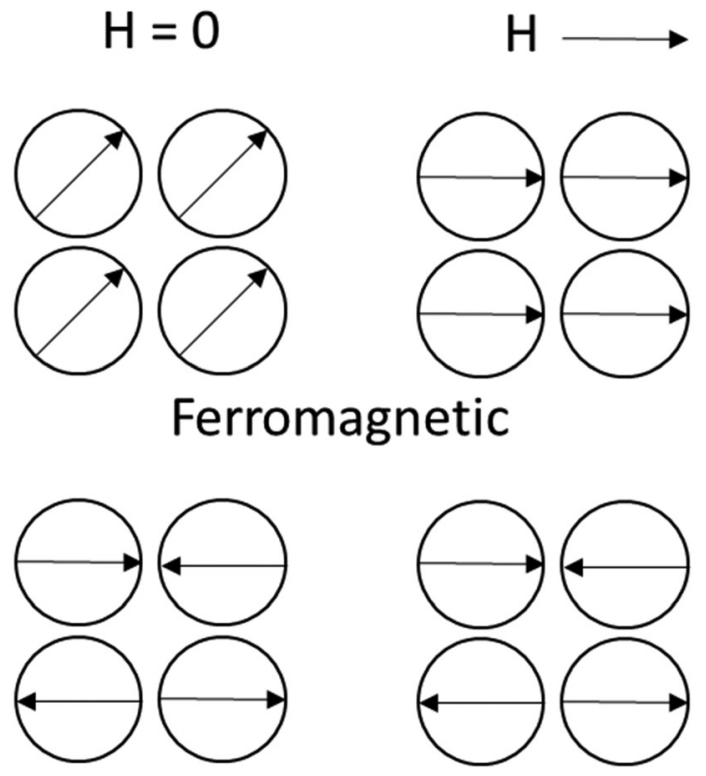

\section{Antiferromagnetic}
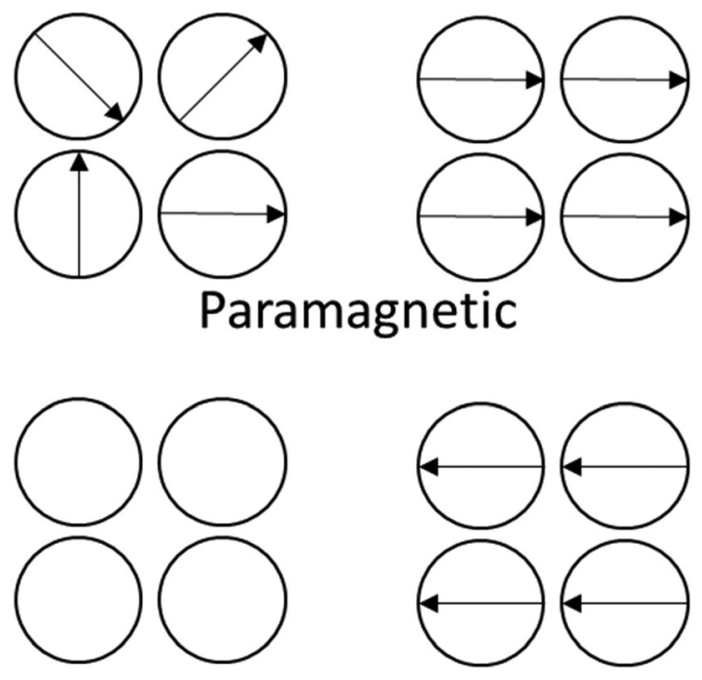

\section{Diamagnetic}

Fig. 3 Illustration of the magnetic dipole moments in magnetic materials with and without an external magnetic field $(H)$.

\section{Intrinsic magnetic moment of cellulose}

Cellulose is a diamagnetic substance. The combination of anisotropy (Table 1) and diamagnetic polarizability makes it susceptible to a certain extent, to manipulation in a magnetic field because the diamagnetic material tends to exclude magnetic flux and the anisotropic particles orient to axis with the most diamagnetic susceptibility perpendicular to the field. ${ }^{29}$ Frka-Petesic et al. ${ }^{30}$ quantified the diamagnetic anisotropy of CNCs by optical birefringence measurements in Cotton-Mouton experiments and confirmed a negative sign of the diamagnetic anisotropy and a diamagnetic susceptibility of $-0.95 \times 10^{-6}$. They further confirmed that the 


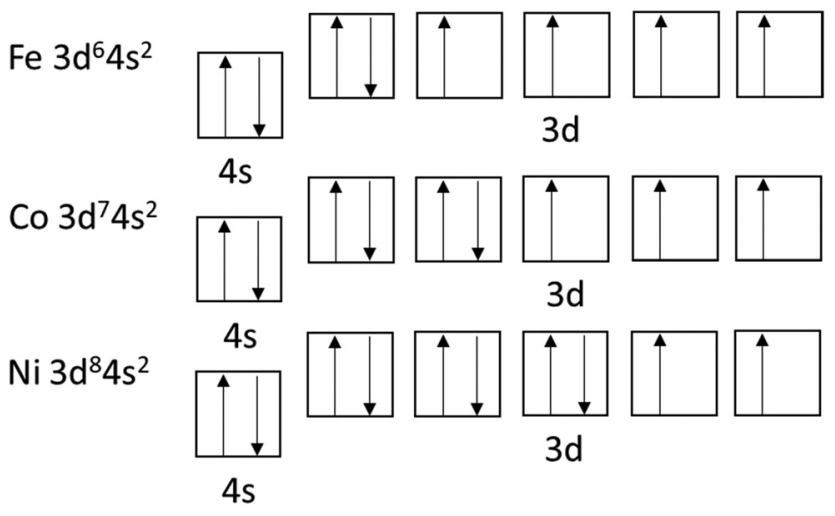

Fig. 4 Ground-state electron configuration of iron, cobalt, and nickel.

rod-like CNCs tended to orient themselves perpendicular to a strong magnetic field.

Indeed, exposure of the elongated CNCs above a critical concentration to a high magnetic field has been demonstrated to result in alignment of the CNCs. ${ }^{31}$ Moreover, the control of $\mathrm{CNC}$ orientation is interesting for liquid crystal materials where, in case of CNCs, either a cholesteric or nematic order is to be manipulated. It has been suggested that cholesteric structure formation is unaffected by the magnetic field, but the pitch (the magnitude of total rotation in the cholesteric order) can be increased and is due to alignment of the individual crystals in the liquid crystal order. ${ }^{32}$ Drying a CNC film in the presence of a $0.2 \mathrm{~T}$ external magnetic field increases the pitch, but the resulting structure is also affected by the drying process. $^{32}$

Furthermore, the unidirectional alignment of cellulose is interesting for creating anisotropic materials that exhibit piezoelectricity $^{33}$ and for control over thermal expansion ${ }^{34}$ and strength $^{35}$ owing to the increase in order. The potential of the aligning cellulose using magnetic fields has been proven mostly in water, but is also found in solvents of higher dielectric permittivity. ${ }^{31} \mathrm{~A}$ field of $7 \mathrm{~T}$ was required to align tunicin CNCs in a film that was prepared in a magnetic field. ${ }^{36}$ The tunicin CNCs are characterized by a length that is greater by a factor of 10 than that of wood CNC varieties. ${ }^{37}$ The length and rigidity that arises from the supramolecular order make it appealing in applications that benefit from the rod-like particle alignment. However, the magnetic field of $7 \mathrm{~T}$ is high. To put this in perspective, we may consider that the typical magnetic resonance imaging (MRI) magnets are 1.5-3 $\mathrm{T}$ and the strongest ones currently available exceed $10 \mathrm{~T} .^{38}$

Mao et al. ${ }^{39}$ revealed that the nematic phase of CNCs was aligned by applying a magnetic field of $0.5 \mathrm{~T}$, while the isotropic phase was not. A field of $1.2 \mathrm{~T}$ applied to cellulose nanowhiskers (i.e., $\mathrm{CNCs}$ ) in a cellulose matrix resulted in pronounced orientation of the nanowhiskers in certain domains, while in other areas the random orientation remained. ${ }^{40}$ A similar field strength, $1.2 \mathrm{~T}$, was used to align cellulose nanowhiskers in a pulp matrix. They found that exposure to the magnetic field aligned the particles, while the wood pulp fibers remained unaligned. ${ }^{41}$ The orientation increased the storage modulus along the direction perpendicular to the magnetic field. It has actually been shown that the effect of the magnetic field on the simple shear and viscoelastic properties is more significant at a lower concentration of cellulose particles, thereby demonstrating that the interacting particles may hinder the orientation. ${ }^{42}$ However, using dilute systems is not practical most of the time for engineering materials that are designed to be solid (dry) and this is a limiting factor for using dilute systems.

Furthermore, in addition to the demand for high field strength, time is a limitation for using the intrinsic diamagnetic property of cellulose for alignment purposes: for example, $0.7 \mathrm{~T}$ and $20 \mathrm{~h}$ has been found to be required for achieving alignment. ${ }^{31}$ On the other hand, $0.56 \mathrm{~T}$ was reported to reach almost perfect alignment in CNC water suspension in less than 200 min. ${ }^{43}$ However, these are still long-time scales, considering the typically required magnetic response time; for example, in devices. A combination of electric and magnetic fields may facilitate shorter times. In fact, to facilitate alignment in a magnetic field $(5 \mathrm{~T})$, an electric field $\left(50 \mathrm{~V} \mathrm{~cm}^{-1}\right.$ at $\left.100 \mathrm{~Hz}\right)$ was applied to wet-spun cellulose fibers. ${ }^{44}$ Either electric and magnetic fields alone or applied simultaneously induced alignment of CNFs. However, the issue of the long time duration required for alignment remains to be resolved.

\section{Synthesis of magnetic cellulose}

It may be that the most feasible method for introducing a magnetic property to cellulose is combining it with ferromagnetic nanoparticles. The main methods of preparation of ferromagnetic cellulose hybrid materials are presented in this chapter and summarized in Table 2.

Table 2 Approaches to render cellulose magnetic

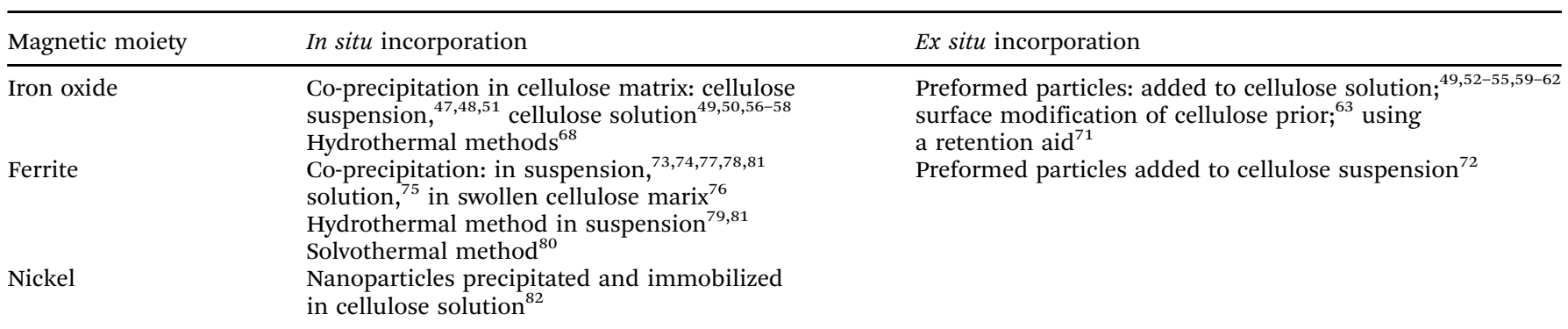




\section{Iron oxide particles}

Magnetite particles are by far the most utilized particles for preparing magnetic cellulose materials. Iron oxide particles and their magnetite phase are typically prepared by co-precipation ${ }^{45,46}$ using iron salt solutions - for example, precursor mixture iron(II), chloride $\mathrm{FeCl}_{2}$, and iron(III) chloride $\left(\mathrm{FeCl}_{3}\right)$. Magnetite particlecellulose hybrids have been synthetized by dissolving the salts of $\mathrm{FeCl}_{2}$ and $\mathrm{FeCl}_{3}$ into a cellulose particle suspension and initiating particle precipitation by changing $\mathrm{pH}$ to alkaline through the addition of a base. ${ }^{47-49}$ Maghemite particles have also been incorporated into cellulose hydrogels using the immersion of preformed hydrogel into iron salts, followed by particle initiation by a shift in the pH level. ${ }^{50}$ The structure of the formed particles via co-precipitation is determined by nucleation and molecular growth events. Nucleation begins by the formation of molecule clusters that function as precipitation points for further development into particles. The particle growth is influenced by mixing and temperature also plays a role; for example, at room temperature, a diameter of 6.5-12.5 $\mathrm{nm}$ was reported for total iron concentration ranging from 0.04 to $0.8 \mathrm{~mol} \mathrm{l}^{-1}$, synthesized in a cellulose matrix, while increase in temperature affected the size distribution and dispersion. ${ }^{51}$

The co-precipitation has been mostly performed in a matrix of various cellulose material hierarchies (Table 1), thereby producing hybrid particles comprising organic cellulose and inorganic iron oxide phases. The same method has been applied to produce magnetic cellulose in solution by first dissolving the cellulose in, for example, $\mathrm{NaOH} /$ urea at low temperature and combining the cellulose solution with pre-formed magnetic particles ${ }^{52-55}$ or dropwise addition of a solution of $\mathrm{FeCl}_{3}$ and $\mathrm{FeCl}_{2}$ into the solution. ${ }^{56,57}$ Cellulose xanthate, that is a soluble intermediate in viscose production and can be regenerated to cellulose, was functionalized with iron oxide particles by adding premade particles as well as in a one-step synthesis by adding an iron source into the xanthate solution. ${ }^{49}$

Furthermore, ionic liquids are a rather new class of cellulose solvents, which are already being used in preparing magnetically functional cellulose: ionic liquids have been used to dissolve the cellulose and iron salts for co-precipation, ${ }^{58}$ mixing together, ${ }^{59-62}$ or grafting ${ }^{63}$ the cellulose and magnetic component. Ionic liquids were also used as a solvent for dissolution and regeneration in the sol-gel transition method to produce cellulose-chitosan magnetic composites. ${ }^{64,65}$

While co-precipitation is a widely used method, there are also other chemical methods, including hydrothermal methods. ${ }^{66}$ Hydrothermal methods for preparing cellulose composite films with $\mathrm{Fe}_{3} \mathrm{O}_{4}$ have been established using $\mathrm{FeCl}_{3}$, trisodium citrate dihydrate, and sodium acetate trihydrate dissolved in ethylene glycol and autoclaved at $200{ }^{\circ} \mathrm{C}$, thereby leading to spherical particles of diameter $243 \pm 72 \mathrm{~nm} .{ }^{67} \mathrm{CNC}-$ $\mathrm{Fe}_{3} \mathrm{O}_{4}$ hybrids were prepared via hydrothermal decomposition of iron(III) acetylacetonate. This was added to a mixture of oleic acid, 1-octadecene, and benzyl ether and heated to form $\mathrm{Fe}_{3} \mathrm{O}_{4}$ nanoparticles. $^{68}$

The majority of iron oxide particles are spherical. However, the synthesis of platelike $\mathrm{Fe}_{2} \mathrm{O}_{3}$ nanoparticles with a size of
$48 \mathrm{~nm}$ and a thickness of $9 \mathrm{~nm}$ in a cellulose matrix with weak ferromagnetic properties and magnetic anisotropy has been reported. ${ }^{69}$

The primary method of affecting the load of particles in the cellulose matrix is by varying the synthesis conditions and the reagent concentrations and ratios. However, the loading can also be adjusted by affecting the accessibility of the selected cellulose hierarchy. The modification of native macrofibres (instead of nanofibrils and regenerated macrofibres) has the likelihood of extending the modification from the surface to the fiber lumen and cell wall. An ultrasound treatment of cellulose fibers increases the amount of iron oxide particles that could be introduced via co-precipitation. ${ }^{70}$ The reasoning for this is the improved accessibility and opening of the nanoscale voids of the cellulose matrix. In addition, the ultrasound synthesis was deemed effective to control the size $(10-100 \mathrm{~nm})$ and the particle distribution of the magnetic iron oxide in the magnetic cellulose composite. ${ }^{70}$ The ultrasound treatment increased the mass of detected iron in the material. The so-called Lumen loading has also been facilitated for iron oxide particles to be incorporated within cellulose fibers by swelling the fibers and using polyethyleneimine (PEI) as a retention aid. ${ }^{71}$

\section{Ferrite particles}

Ferrites are formed in the reaction of iron oxide with another metal (e.g., cobalt, nickel, copper, aluminum, and manganese). Cobalt ferrite $\left(\mathrm{CoFe}_{2} \mathrm{O}_{4}\right)$ particles are commonly used to prepare magnetic cellulose via co-precipitation. ${ }^{72}$ They can be synthetized using iron(II) sulfate $\left(\mathrm{FeSO}_{4}\right)$ and cobalt(II) chloride $\left(\mathrm{CoCl}_{2}\right)^{73,74}$ or $\mathrm{FeCl}_{2}$ and $\mathrm{CoCl}_{2}{ }^{75} \mathrm{CoFe}_{2} \mathrm{O}_{4}$ particles were synthetized in a cellulose aerogel via co-precipitation in a swollen cellulose network followed by freeze drying, which led to the production of particles of diameter $98.5 \mathrm{~nm} .{ }^{76}$ An impressive $95 \%$ loading has been achieved by co-precipitation of cobalt ferrite in a CNF matrix. The CNFs acted as templates for the non-agglomerated growth of ferromagnetic nanoparticles (diameter, 40-120 nm). ${ }^{77}$ The same procedure has been demonstrated in CNC hybrid materials, but with a lower loading of $7 \mathrm{wt} \%{ }^{78}$ Electron microscopy visualization of the stages of cellulose (CNC) prior and after treatment with cobalt and iron precursor salts, after precipitation and purification are presented in Fig. 5a, b, c and $\mathrm{f}$, respectively. Purification via magnetic decanting is visualized in Fig. $5 \mathrm{~d}$ and e. The homogenous formation of magnetic particles in the cellulose matrix is evident (Fig. 5f).

Copper cobalt ferrite $\left(\mathrm{Cu}_{0.5} \mathrm{Co}_{0.5} \mathrm{Fe}_{2} \mathrm{O}_{4}\right)$ has been synthesized in situ by controlled hydrothermal chemistry and immobilized on CNCs. ${ }^{79}$ In addition, positive electric charge manganese ferrite particles $\left(\mathrm{MnFe}_{2} \mathrm{O}_{4}\right)$ have been prepared using the solvothermal method using $\mathrm{FeCl}_{3}$ and $\mathrm{MnCl}_{2} \cdot{ }^{80}$ The precipitation of zinc ferrite $\left(\mathrm{ZnFe}_{2} \mathrm{O}_{4}\right)$ nanoparticles onto the surface of cellulose fibers has also been established. ${ }^{81}$

\section{Nickel-containing particles}

Nickel nanoparticle-cellulose-grafted graphite oxide nanocomposites have been proposed for applications in biosensors 


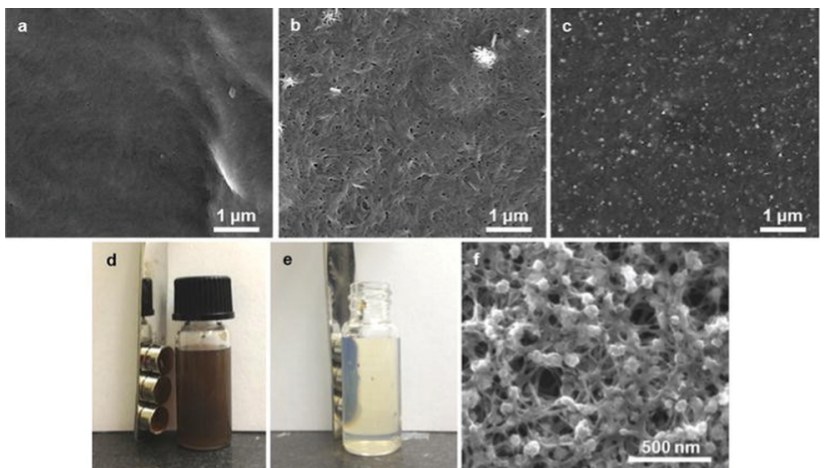

Fig. 5 Electron microscopy images of CNCs (a), precursor salt-treated CNCs (b), and magnetic CNCs (c) deposited on silicon substrates. The magnetic CNC phase (d) was subjected to magnetic separation with $\mathrm{NdFeB}$ magnets (e) and imaged (f). Image reprinted by permission from Nypelö et al. ${ }^{78}$

and biocatalysts. ${ }^{82}$ Moreover, the sputtering of nickel nanoparticles on carbonized cotton has also been reported. ${ }^{83}$

\section{Properties of cellulose-magnetic particle hybrid materials}

Cellulose-magnetic hybrid materials represent the possibility of cellulose functionalization with a magnetic property. The magnetic particles are primarily responsible for the ferromagnetic character that is introduced into the cellulose material.

\section{Magnetic properties}

The magnetic properties of a material are characterized by magnetization (that is, the magnetic moment per volume or mass $\left(\mathrm{emu} \mathrm{g}^{-1}\right)$ ) and the response of the material to the magnetic field, known as magnetic induction (Tesla). Magnetic properties are measured and presented as magnetization versus the applied magnetic field. In ferromagnetic materials, the magnetization becomes saturated (reaches a plateau) above a certain applied field and is quantified by a saturation magnetization (i.e., a magnetic field that leads to maximum magnetization). Coercivity characterizes the ability of a ferromagnetic material to withstand an external magnetic field without demagnetization. Superparamagnetism is a property of small particles where magnetization can flip direction. The decrease in the domain size leads to a decrease in coercivity. ${ }^{29}$ Moreover, the type of magnetism sought depends on the application. In data storage applications, the particles need to have a switchable magnetic state that is not affected by temperature fluctuations. Typically, large coercivity is sought. ${ }^{29}$ For biomedical applications, superparamagnetism at room temperature is a prerequisite, along with high magnetization, to be directed into the body ${ }^{84}$ The materials also need to be (colloidally) stable in water and in physiological conditions, with the ability to diffuse in tissue. For in vivo applications, a biocompatible surface is required, and magnetite and maghemite are commonly used in vivo. Cobalt and nickel, being toxic, are less preferred.
In a hybrid material of $\mathrm{CNC}-\mathrm{CoFe}_{2} \mathrm{O}_{4}$, a maximum magnetization saturation of $12.96 \mathrm{emu} \mathrm{g}^{-1}$ has been obtained ${ }^{85}$ while the $\mathrm{CoFe}_{2} \mathrm{O}_{4}$ alone was discussed to reach a saturation magnetization of $60 \mathrm{emu} \mathrm{g}^{-1}$. Furthermore, CNF saturation magnetization of $14.17 \mathrm{emu} \mathrm{g}^{-1}$, with $20 \%$ loading of $\mathrm{Fe}_{3} \mathrm{O}_{4}$ nanoparticles has been reported. ${ }^{86} \mathrm{Fe}_{2} \mathrm{O}_{3}$ as synthetized in a cellulose matrix exhibited a saturation magnetization of $98.39 \mathrm{emu} \mathrm{g}^{-1}$ and the coercivity was $32.68 \mathrm{Oe}^{87}$ In addition, cellulose macrofibers modified with cobalt ferrite particles presented a saturation magnetization of approximately $8.0 \mathrm{emu} \mathrm{g}^{-1}$ and a coercivity higher than 200 Oe. $^{72}$ It was indicated that the properties are adequate for magnetic recording applications.

\section{What is the benefit of cellulose in magnetic hybrid structures?}

Perhaps the most important asset of cellulose in magnetic materials is the diversity of the available natural and humanmade particles and fiber forms (Table 1). In addition to the pulp fibers and regenerated fiber filaments, ${ }^{88}$ the cellulose hierarchy that has recently become popular in magnetic demonstrations are the nanocelluloses. One of the benefits of using nanocelluloses for magnetic hybrids includes the fact that the nanocelluloses can be formed into transparent films. ${ }^{89}$ The nanocellulose films resemble plastic films, and it is easy to understand the excitement generated by this potential development: it has the ability to replace synthetic plastics with natural materials. Consequently, nanocellulose films with magnetic particles are also transparent (up to a certain loading). A transparency of $86 \%$ and a tensile strength of $170 \mathrm{MPa}$ was reported with $5 \%$ of $\mathrm{Fe}_{3} \mathrm{O}_{4}$-particle loading. ${ }^{86}$

The challenge of nanoparticles (of any kind) in materials engineering is their dispersion in a manner that allows aggregation to be controlled. An asset of using, for example, CNFs as the templates for growing particles ${ }^{78}$ is the ability to prevent the subsequent free migration of particles as well as the evident aggregation.

Nanoscale cellulose fibers used to carry magnetic moieties in hybrid materials have been created by transferring cellulose solutions into fibers via electrospinning. Electrospinning of CNC- $\mathrm{Fe}_{3} \mathrm{O}_{4}$ particles in a poly(3-hydroxybutyrate-co-3-hydroxyvalerate) and polyethylene glycol matrix ${ }^{47}$ as well as cobalt ferrite particles in a polyvinyl alcohol matrix ${ }^{78}$ has been used to prepare continuous nanofibers with a smaller diameter than pulp or textile fibers. Nanofibers with a small diameter are often sought in biomedical applications in which a high surface area is advantageous for interactions with tissue and cells. Another emerging field of fiber spinning is the wet spinning of suspensions containing nanocelluloses into filaments, which also involves the opportunity to incorporate magnetic particles into these filaments. ${ }^{90}$

In addition to the hierarchies listed in Table 1, there are a few additional human-made formats that have been popular in magnetic cellulose endeavors. Cellulose beads or spheres are often prepared via the dissolution of cellulose and their magnetic property is created by the incorporation of iron oxide particles in the beads. ${ }^{51,91-96}$ Cellulose has been combined with other hydrophilic polysaccharides and polymers in the creation 
of cellulose-hydroxyapatite magnetic beads ${ }^{97}$ and in cellulosechitosan microspheres. ${ }^{98}$ The beads are mostly used in protein detection $^{96}$ or in encapsulation and separation applications. Moreover, CNCs are used in microbead formation (or oil stabilization $^{99}$ ) due to their specific property of assembling at an oil-water interface and functioning as a Pickering stabilizer to form a shell around the bead. ${ }^{100,101}$

Cellulose-magnetic hydrogels are a large material group used for separation and immobilization of biomolecules. ${ }^{102}$ A rather straightforward approach of preparation is the dissolution of cellulose followed by crosslinking into a gel and incorporation of iron oxide particles into the hydrogel. ${ }^{103}$ Cellulose along with other hydrophilic polymers (polyvinylalcohol and chitosan) have been demonstrated to form gels that also enclose magnetic particles ${ }^{104,105}$ and are used for the removal of heavy metals, like lead $(\mathrm{Pb})$, by using the carboxylate groups of cellulose as an active site for $\mathrm{Pb}$ retention. ${ }^{106} \mathrm{Mag}$ netic beta-cyclodextrin-cellulose hydrogels have been prepared by epoxidation of cellulose with cyclodextrin, followed by dispersing $\mathrm{Fe}_{3} \mathrm{O}_{4}$ particles in the mixture and finally coagulating the system in a $\mathrm{CaCl}_{2}$ bath into hydrogel microbeads. ${ }^{107}$ Quaternized xylan and CNCs were used to create a network via ionic crosslinking and formed a hydrogel, where magnetic functionality was incorporated via $\mathrm{Fe}_{3} \mathrm{O}_{4}$ synthesis within the reinforced hydrogel matrix. ${ }^{108}$

\section{Alignment in magnetic cellulose materials}

Aligned magnetic nanoparticles in a cellulose matrix were prepared by embedding a cellulose solution with $\mathrm{Fe}_{3} \mathrm{O}_{4}$ nanoparticles subjected to magnetic orientation, regeneration to cellulose, and stretching the composite to magnify the alignment. ${ }^{109}$ CNCs were aligned in a polymer matrix by first aligning them in the precursor system followed by curing using polymerization. ${ }^{110}$ TunicateCNCs were demonstrated as a filler for rubber to produce rubber composites with an alignment and magnetic functionality. ${ }^{111}$ The preparation procedure is simple exposure of the system to a magnetic field and then curing. Overall alignment is attained by the alignment of the anisotropic cellulose particles that carry iron oxide particles. A simple approach for aligning macrofibers decorated with magnetic particles has been demonstrated using permanent magnets in a flow cell. ${ }^{112}$

Furthermore, Yoshitake et al. ${ }^{113}$ demonstrated that films where the CNCs and magnetite $\left(\mathrm{Fe}_{3} \mathrm{O}_{4}\right)$ particles are oriented can be directed by an external magnet. Rectangular strips of films assembled the draw direction vector parallel to the field vector. The manipulation of magnetically modified cellulose with a magnetic field is more instantaneous than the manipulation of neat cellulose and requires, in general, magnets with lower strength-Yoshitake et al. ${ }^{113}$ used a $0.15 \mathrm{~T}$ bar magnet to move the hybrid materials.

\section{Cellulose in magnetic devices}

This section presents demonstrations of devices that benefit from the combination of cellulose and magnetic substances.
Here, a device is defined as a system adapted for a particular purpose.

\section{Loudspeakers}

An application of cellulose in magnetic devices that is tangible in everyday life is the demonstration of magnetic cellulose films in loudspeakers. A thin prototype loudspeaker has been proposed, where a cellulose- $\mathrm{CoFe}_{2} \mathrm{O}_{4}$ membrane is driven to generate music through a static coil. ${ }^{114}$ In a traditional loudspeaker, there is a membrane that is attached to the voice coil that moves in a magnetic gap and causes a membrane to vibrate and produce a sound. The setup by Galland et al. ${ }^{114}$ with a magnetic cellulose membrane was to make an external magnet unnecessary by introducing the magnetic cellulose membrane. The magnetic membrane in the loudspeaker prototype is depicted in Fig. 6. The benefit of using CNFs as the template for magnetic nanoparticles and in the membranes was that the nanoparticles attached to the fibrils ensured a homogeneous particle distribution. The membranes had an impressive strength of $100 \mathrm{MPa}$ and a stiffness of $5 \mathrm{GPa}$ at 60 wt $\% \mathrm{CoFe}_{2} \mathrm{O}_{4}$ loading. ${ }^{114}$ The strength is due to the $\mathrm{CNF}$ matrix: CNF films have often been reported with a tensile strength of above $200 \mathrm{MPa} .{ }^{115,116}$

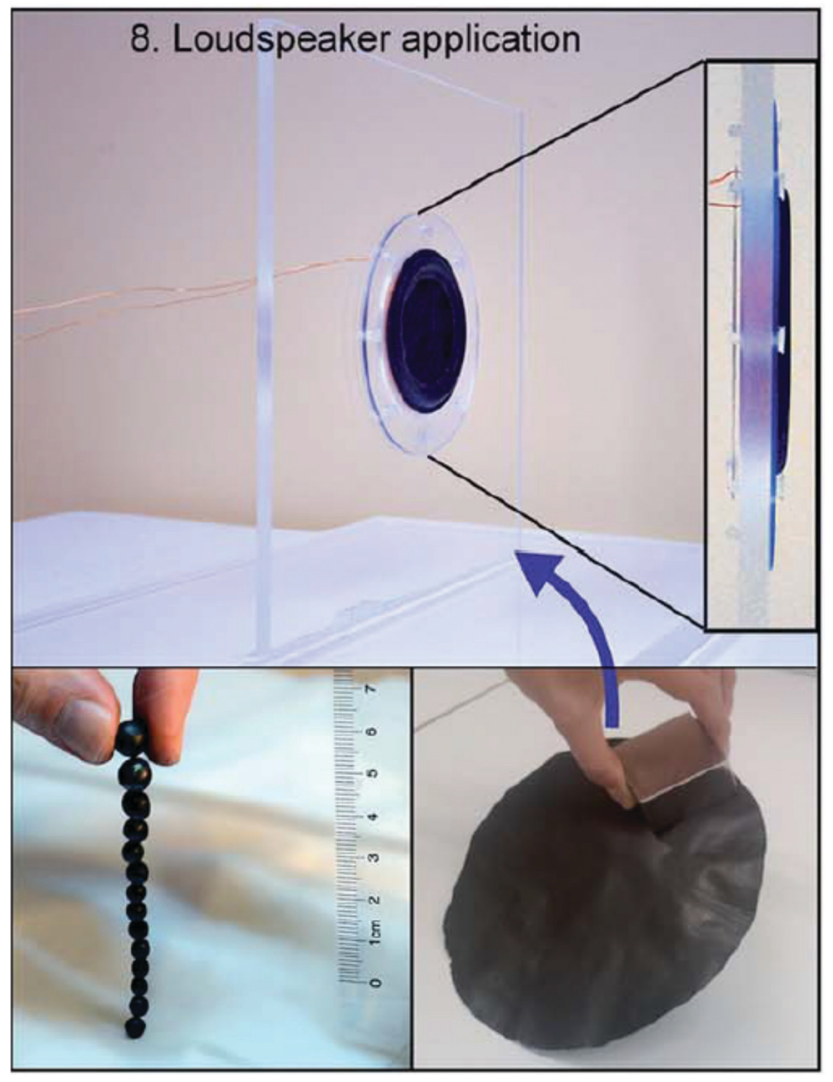

Fig. 6 A magnetic membrane (bottom right) prepared by vacuum filtration of magnetic nanofibril suspension in a thin prototype loudspeaker operating without an external magnet (upper figure). Hard permanently magnetized spherical beads are shown in bottom left figure. The image has been reproduced from Galland et al. ${ }^{114}$ under CC BY-NC 3.0 license. 
Tarres et $a .^{117}$ suggested a simplified procedure for the preparation of a loudspeaker membrane, in which the in situ co-precipitation was replaced by mixing CNF and magnetite nanoparticles and using cationic starch for retention. They reported lowered strength from $80 \mathrm{MPa}$ to $40 \mathrm{MPa}$ with $60 \%$ loading and a Young's modulus of $5.4 \mathrm{GPa}$. The stiffness of the membranes was found to limit the use. The authors suggested consideration of plasticizers or cellulose macrofibers to improve the membrane properties.

One of the benefits of using cellulose fibers and nanofibers in membranes is that they enable the formation of films, sheets, and paper materials that are flexible, because flexible fibers form an entangled network that can be typically rolled and folded in a manner similar to paper. ${ }^{118}$ However, this flexibility is accompanied with lacking thermo-moldability and, occasionally, instability in mechanical performance that stems from humidity sensitivity. The mechanical stability of $\mathrm{CoFe}_{2} \mathrm{O}_{4}$-loaded nanocellulose composites has been addressed by low temperature heat treatment and impregnation with an epoxy resin, which further strengthens the nanofiber networks. ${ }^{119}$

\section{Optical devices}

The transparency of nanocellulose films with magnetic functionality is often mentioned to be beneficial for magneto-optic use. ${ }^{120,121}$ However, thus far, the optical use considerations of magnetic cellulose do not utilize the magneto-optic effect as such but rather the cellulose light-interactions combined with the magnetic character of the material. Utilizing the ability of CNCs to form cholesteric phase has inspired demonstration toward chiral photonic materials. The spacing between the rod-shaped nanoparticles as well as the chirality are essential for provoking light-cellulose interactions. The combination of magnetic functionality and optically active structure can be of interest for future magnetic cellulose materials for optical devices. Chen et al. ${ }^{122}$ incorporated iron oxide particles in CNCs via co-precipitation in the cellulose matrix. The modified particles were mixed with neat CNCs that enabled the formation of films that exhibited liquid crystalline cholesteric ordering. A field strength of $7 \mathrm{mT}$ was adequate to tune the chiral nematic pitch of the cholesteric phase (Fig. 7).

Using the magnetic functionality combined with optical activity has been demonstrated as proof of the concept of advanced multimodal protection of clothing against counterfeiting. ${ }^{123,124}$ The multifunctionality was obtained by modifying cellulose fibers with nanoparticles based on lanthanide-doped fluorides and magnetite that were luminescent and magnetic. As the mechanical properties were maintained, the fibers retained their applicability for use in textiles.

\section{Magnetic hyperthermia}

Magnetic hyperthermia aims to produce local heating. One of its applications is in medicine in the treatment of tumors via localized heating - that is, to facilitate the deterioration of selected malignant tissue. A cellulose hybrid material of CNCs decorated with $\mathrm{CoFe}_{2} \mathrm{O}_{4}$ particles has been shown to heat via the hyperthermia effect, when the aqueous dispersion was

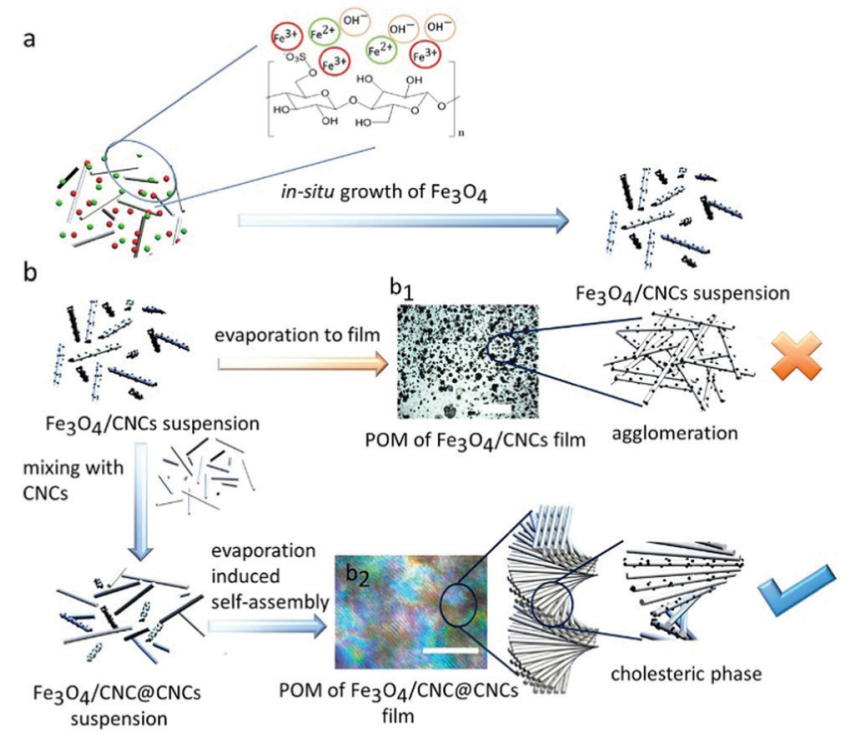

Fig. 7 A schematic presentation of (a) in situ growth of $\mathrm{Fe}_{3} \mathrm{O}_{4}$ nanoparticles onto $\mathrm{CNCs}$ to form an $\mathrm{Fe}_{3} \mathrm{O}_{4} / \mathrm{CNC}$ suspension; (b) evaporation of $\mathrm{Fe}_{3} \mathrm{O}_{4} / \mathrm{CNC}$ suspensions to obtain $\mathrm{Fe}_{3} \mathrm{O}_{4} / \mathrm{CNC}$ film with agglomeration of cholesteric order using $\mathrm{Fe}_{3} \mathrm{O}_{4} / \mathrm{CNC}$ suspension or $\mathrm{Fe}_{3} \mathrm{O}_{4} / \mathrm{CNC}$ suspension with neat CNCs, respectively. Scale bars: $100 \mu \mathrm{m}$ for $b_{1}$ and $10 \mu \mathrm{m}$ for $b_{2}$. Reprinted with permission from Chen et al. ${ }^{122}$ Copyright (2020) American Chemical Society.

exposed to an alternating magnetic field (200 Gauss, $869 \mathrm{~Hz}) .^{78}$ It is an intriguing idea in terms of not only manufacturing a new material for the magnetic hyperthermia treatment but opening consideration of the opportunities of rod-like CNCs in in vivo applications. However, the toxicological evaluation of CNCs are still in progress for their use in vivo.

\section{Storage systems}

The addition of magnetic $\mathrm{CNC}-\mathrm{Fe}_{3} \mathrm{O}_{4}$ hybrids into phase change material matrices led to materials that could be used to store solar or magnetic heating energy. ${ }^{47}$ The operating temperatures between 44 and $61{ }^{\circ} \mathrm{C}$ and energy storage capacity up to $83 \mathrm{~J} \mathrm{~g}^{-1}$ were achieved and the phase change materials were demonstrated for drying agricultural products.

\section{Magnetic shielding}

There is vivid dissemination regarding the suitability of magnetic cellulose hybrid materials for magnetic shielding. Recently, electromagnetic shielding with cellulose aerogels was reviewed by Wan et al. ${ }^{125}$

Magnetic shielding refers to protecting objects from a magnetic field by the installation of another magnetic field. The magnetic field is redirected by the additional field that is generated by a ferromagnetic material. Successful magnetic shielding was achieved with iron oxide- ${ }^{67}$ and cobalt ferrite- ${ }^{78}$ decorated cellulose materials. The shielding effect can be quantified by measuring current in the film applied with and without an external magnetic field in a setup where the magnetic field-generating films are placed on a magnet. ${ }^{67,109}$ In addition, the alignment of the magnetic domains in such 
films allowed a specific response depending on the alignment in the film and of the magnetic field. Along the direction parallel to the magnetic orientation, the current instantly decreased from 7.4 nA to $5.1 \mathrm{nA}$ when an additional magnetic field was introduced. In a perpendicular direction, the change was from $3.8 \mathrm{nA}$ to $3.2 \mathrm{nA}$, thereby demonstrating that the directionality in the material modulates the magnetic shielding property. ${ }^{109}$

A combination of the chiral nematic structural features of mesoporous photonic cellulose and the magnetic properties of $\mathrm{CoFe}_{2} \mathrm{O}_{4}$ has also been used in electromagnetic interference shielding. The cellulose template was mesoporous and was a result of templating with cholesteric CNCs and urea-formaldehyde. ${ }^{126}$

\section{Magnetic separation and food}

Magnetic-based separation is a popular example of for magnetic cellulose hybrid materials. ${ }^{74,127-129}$ The role of the magnetism is to act as a stimulus for the collection of the target molecules. The cellulose acts as a carrier for the magnetic functionality or as the absorbent. For example, in so-called stir bar sorptive-dispersive microextraction, a magnetic stir bar is coated with magnetic (hybrid) material. Stirring results in the release of the particles into the matrix available for adsorbing the target molecules. When the stirring is stopped, the particles are collected onto the bar. ${ }^{73}$

Magnetic cellulose composite aerogels, films, and papers have been demonstrated for the adsorption of heavy metals, ${ }^{57,130-138}$ dyes, ${ }^{139-144}$ drugs,${ }^{145}$ immobilization of enzymes and proteins, ${ }^{93,146-151}$ bacteria, ${ }^{54}$ and as carriers for drugs. ${ }^{152}$ Independent of the type of magnetic particle, the removal of heavy metals or dyes from municipal and industrial wastewater is a challenge that has been solved in numerous prior studies. ${ }^{153-158}$ Oil absorption and separation in general is one of the popular separation applications for magnetic cellulose. ${ }^{159-163}$ The release of encapsulated substances has also been demonstrated using exposure to a magnetic field and for controlled delivery of drugs for cancer treatment. ${ }^{164,165}$

Molecular imprinting and preparing cavities of a specific size and shape within a matrix has been used for preparing magnetic cellulose materials as adsorbents, for example, fluoroquinolones and artesunates. ${ }^{129,166-168}$ In addition, metal organic frameworks have been recently combined with magnetic cellulose for separation applications. ${ }^{169,170}$

Applications of magnetic cellulose materials in food are scarce perhaps because cellulose is a non-dietary fiber. Yet, an innovative approach for preparing edible coating on pineapples (and other food as well) with a nanocellulose-chitosaniron oxide has been published to maintain human health with iron-fortified materials. ${ }^{171}$

\section{Visualization}

Imaging of soft organic matter like cellulose using electron microscopy and several scanning techniques often has the shortcoming of low contrast. This can be circumvented with sputtering and labeling. Iron is readily distinguishable within a carbon network, and energy dispersive X-ray spectroscopy

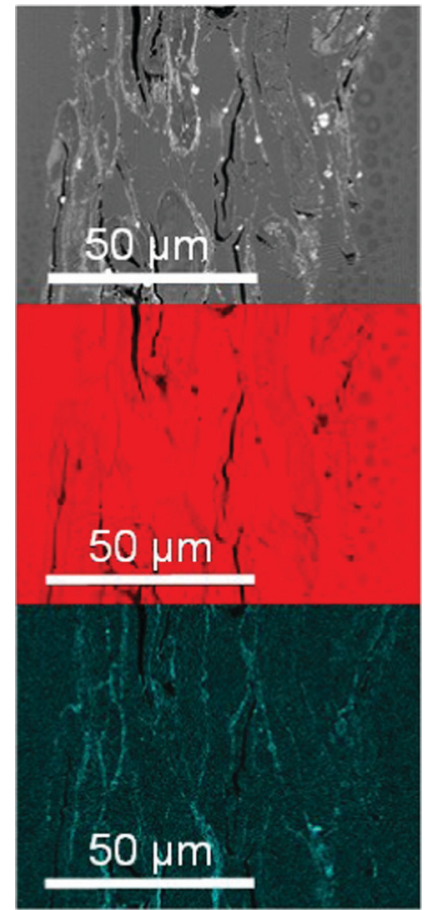

Fig. 8 The cross-section of sheets containing $10 \%$ of nanoparticlelabeled materials. The elemental distribution was evaluated by energy dispersive X-rays, thereby revealing a uniform distribution of carbon (red), while the distribution of cobalt (cyan) has the form of fibrils. The image is reprinted from Hobisch et al. ${ }^{172}$ Copyright (2021), with permission from Elsevier.

mapping of iron in the cellulose matrix has been performed for the analysis of magnetic cellulose material. ${ }^{113,124}$ Another challenge of visualization of cellulose materials is that the various hierarchies of cellulose are not easily distinguished because they have the same chemical composition. Hobisch et $a l .{ }^{172}$ resolved this using magnetic nanoparticles to label a certain proportion of the cellulose particles in paper and enable their visualization within the fiber matrix (Fig. 8).

CNC- $\mathrm{Fe}_{3} \mathrm{O}_{4}$ hybrids have been applied as MRI contrast agents, where the hybrid in fact showed negligible in vitro cytotoxicity and excellent contrast enhancement compared to commercial and clinical agents. ${ }^{68}$

\section{Outlook}

Most magnetic cellulose materials are prepared by coprecipitation of iron (and cobalt) salts in a cellulose suspension, which leads to the formation of magnetic particles in the cellulose matrix. It has been suggested that the interaction first develops with the precursor salts when $\mathrm{Co}^{2+}$ and $\mathrm{Fe}^{3+}$ ions are incorporated into the cellulose molecules via electrostatic attraction between the electron-rich oxygen atoms in the cellulose molecules and the electropositive metal cations (schematic presentation in Fig. 9). ${ }^{173}$ It is seen that this reduces the mobility of the metal ions, enhances the formation of, for example, $\mathrm{CoFe}_{2} \mathrm{O}_{4}$ nuclei, and stabilizes nanoparticles on the 


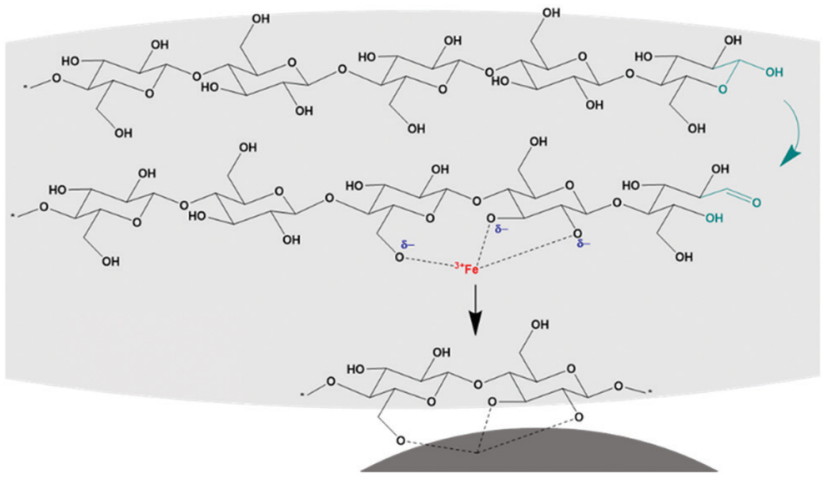

Fig. 9 A scenario of coordination of a metal ion (red) with cellulose molecule or hierarchy (presented by light grey area) that. The nucleation into particles (dark grey), via co-precipitation, leads to cellulose hybrids. Reducing end group (green, the arrow indicates the two available forms, the open form and hemiacetal form) is available for modification. The asterisk $\left(^{*}\right)$ indicates the fact that the cellulose chain continues.

cellulose surface. Discussions in regard of particles formed separately and then combined with cellulose assign the interaction between cellulose and the nanoparticles to a coordinate bond between $\mathrm{Fe}_{3} \mathrm{O}_{4}$ and hydroxyl group of cellulose. ${ }^{67}$ The improvement in thermal stability has been considered as evidence of the interaction between hydroxyl groups and magnetic particles. ${ }^{48}$ The co-precipitation of iron oxide particles leads to strong interaction as demonstrated by the fact that the nanoparticles remained attached even under intense sonication. ${ }^{174}$ Combining preformed particles and CNCs have been reported to lead to random attachment of the magnetic nanoparticles on the cellulose due to the ionic interaction that is distributed along the cellulose. ${ }^{175}$ On the other hand, the mere immersion of biopolymers in an $\mathrm{MnFe}_{2} \mathrm{O}_{4}$ nanoparticle dispersion resulted in no observed interaction between the cellulose and its magnetic components. ${ }^{176}$

The question of the nature and the strength of the bond between the magnetic particles and cellulose after co-precipitation appears to have been established; however, it continues to be discussed. In the case that it indeed is an ionic interaction that guides the location of the magnetic particles on cellulose, the location of the magnetic particles cannot be controlled unless the location of the ionic interaction source on cellulose can be controlled. Furthermore, a method of deliberately depositing the particles on distinct locations of the cellulose particle could allow anisotropy created by magnetic particle location on the cellulose hierarchy rather than by the shape of the cellulose particle only. Perhaps, it actually would be easier and more effective to facilitate the directionality by controlling the location of the magnetic particles than the alignment of cellulose particles. In that case, the use of the reducing end group (Fig. 9) is an opportunity that has not been exploited yet but could provide means of controlling magnetic anisotropy.

Furthermore, the utilization of the electrostatic attraction of oppositely charged molecules has been used to further amplify combining cellulose and magnetic materials by using a cationic polyelectrolyte as an anchoring layer between CNCs and
$\mathrm{Fe}_{3} \mathrm{O}_{4}$ nanoparticles. ${ }^{177}$ Moreover, iron oxide nanoparticle surface charge was manipulated by $\mathrm{pH}$ adjustment and was then used for self-assembly of the positively charged particles on the negatively charged CNCs. ${ }^{175}$ However, the utilization of the electrostatic interactions for loading cellulose materials with magnetic particles allows less control of the location of the particles than, for example, the specific modification of the reducing end of cellulose.

Covalent bonding of the nanoparticles around the cellulose particles has been established by preparing amine functionalized iron oxide particles and coupling them to carboxylic acid containing CNFs via a coupling reaction involving 1-ethyl-3-(3dimethylaminopropyl)carbodiimide hydrochloride and $N$-hydroxy succinimide (EDC-NHS) ${ }^{178}$ In addition, $\mathrm{CNC}-\mathrm{Fe}_{3} \mathrm{O}_{4}$ hybrids were prepared by covalently linking the cellulose with citric acid and incorporating magnetic nanoparticles in this matrix. ${ }^{68} \mathrm{~A}$ system of cellulose powder, PEI, and crosslinked magnetic nanoparticles using glutaraldehyde has been used for preparing a crosslinked material. ${ }^{156}$ Similarly, epichlorohydrin has been employed in a system of cellulose solution, PEI, and magnetic particles to create a crosslink between the cellulose and PEI. ${ }^{179}$

The application of magnetic cellulose in devices like loudspeakers indeed is becoming a reality. However, cellulose may also have negative effects on the properties of the device due to its tendency to absorb moisture, which may have an impact on the stability of the device. These issues need to be addressed in future research. Moreover, the flammability of cellulose may also be a concern. Fortunately, magnetic particles can provide flame retardancy. ${ }^{180,181}$ The presence of magnetic nanoparticles in the composite effectively increased char yield from $8 \%$ in an oxidized cellulose matrix to $25 \%$ and decreased the gas-phase products. The addition of phosphoric acid into magnetic cellulose fibers is another route to increasing the flame resistance of cellulose composites. ${ }^{180}$

The future applications of magnetic cellulose are likely to continue to concentrate on the separation of molecules and contaminants. However, there is much to explore regarding the spectacular properties of cellulose nanofibers and cellulose nanocrystals, along with the possibility to introduce a magnetic functionality. The high aspect ratio of cellulose nanofibers can provide a strong and flexible matrix for smart membranes for example. Moreover, the liquid crystalline phases of CNCs are to be used in optical devices.

\section{Conclusions}

Equipping cellulose with a magnetic functionality is motivated by the renewable, abundant, and non-toxic nature of cellulose materials, thereby making it an appealing substrate for hosting magnetic functionality. The co-precipitation of iron oxide or ferrite particles in a matrix of cellulose fibers, solution, nanofibers, and particles typically lead to a hybrid material in which the cellulose and the magnetic particles are intimately connected. The nature of the connection and, more importantly, the control of the nucleation location of the magnetic particles 
are ongoing discussion topics and challenges that amplify the impact of the magnetic cellulose particles in materials technology. Another future direction for research is to take advantage of the properties of cellulose nanomaterials that enable the production of innovative materials with properties that differ from those of paper but with the benefit of the same cellulose chemistry.

\section{Author contributions}

TN: conceptualization, writing, reviewing, and visualization.

\section{Conflicts of interest}

There are no conflicts to declare.

\section{Acknowledgements}

Wallenberg Wood Science Center, Area of Advance Materials at Chalmers University of Technology and Excellence Initiative Nano at Chalmers University of Technology are acknowledged for the funding provided. I am grateful to Stefan Spirk for generously sharing his knowledge regarding inorganic materials and their magnetic behavior as well as providing input on the manuscript.

\section{Notes and references}

1 norexeco, https://www.norexeco.com/pulp/, (accessed Auguest 15, 2021).

2 fao, http://www.fao.org/forestry/statistics/80938/en/, http:// www.fao.org/forestry/statistics/80938/en/, (accessed August 15, 2021).

3 W. E. Hillis, Wood Sci. Technol., 1984, 18, 281-293.

4 K.-Y. Lee, Y. Aitomäki, L. A. Berglund, K. Oksman and A. Bismarck, Compos. Sci. Technol., 2014, 105, 15-27.

5 C. Miao and W. Y. Hamad, Cellulose, 2013, 20, 2221-2262.

6 E. C. Ramires and A. Dufresne, Advances in polymer nanocomposites, Woodhead Publishing Ltd, 2012, p. 131.

7 V. K. Thakur and M. K. Thakur, Carbohydr. Polym., 2014, 109, 102-117.

8 N. Sriplai and S. Pinitsoontorn, Carbohydr. Polym., 2021, 254, 117228.

9 W. Hu, S. Chen, J. Yang, Z. Li and H. Wang, Carbohydr. Polym., 2014, 101, 1043-1060.

10 A. Gennari, A. J. Fuhr, G. Volpato and C. F. Volken de Souza, Carbohydr. Polym., 2020, 246, 116646.

11 H. Sixta, Handbook of pulp, Wiley-VCH, 2006.

12 A. Dufresne, Mater. Today, 2013, 16, 220-227.

13 Y. Habibi, L. A. Lucia and O. J. Rojas, Chem. Rev., 2010, 110, 3479-3500.

14 E. Kontturi, P. Laaksonen, M. B. Linder, A. H. Gröschel, O. J. Rojas and O. Ikkala, Adv. Mater., 2018, 30, 1703779.

15 R. Kádár, M. Fazilati and T. Nypelö, Cellulose, 2020, 27, 2003-2014.
16 R. Kádár, S. Spirk and T. Nypelö, ACS Nano, 2021, 15(5), 7931-7945.

17 J. Chen, Textiles and Fashion, Elsevier, 2015, pp. 79-95.

18 A. Michud, M. Tanttu, S. Asaadi, Y. Ma, E. Netti, P. Kääriäinen, A. Persson, A. Berntsson, M. Hummel and H. Sixta, Text. Res. J., 2016, 86, 543-552.

19 D. Klemm, B. Philipp, T. Heinze, U. Heinze and W. Wagenknecht, Comprehensive Cellulose Chemistry, Wiley, Weinheim, Germany, 1998.

20 S. Kalia, A. Dufresne, B. M. Cherian, B. Kaith, L. Avérous, J. Njuguna and E. Nassiopoulos, Int. J. Polym. Sci., 2011, 2011, 1-35.

21 W. Y. Hamad, Cellulose nanocrystals: properties, production and applications, John Wiley \& Sons, 2017.

22 T. Saito, M. Hirota, N. Tamura, S. Kimura, H. Fukuzumi, L. Heux and A. Isogai, Biomacromolecules, 2009, 10, 1992-1996.

23 Y. Qing, R. Sabo, J. Y. Zhu, U. Agarwal, Z. Cai and Y. Wu, Carbohydr. Polym., 2013, 97, 226-234.

24 C. Salas, T. Nypelö, C. Rodriguez-Abreu, C. Carrillo and O. J. Rojas, Curr. Opin. Colloid Interface Sci., 2014, 19, 383-396.

25 O. Nechyporchuk, M. N. Belgacem and J. Bras, Ind. Crops Prod., 2016, 93, 2-25.

26 M. Ek, G. Gellerstedt and G. Henriksson, Pulping chemistry and technology, Walter de Gruyter, 2009.

27 E. Sjöström, Wood chemistry: fundamentals and applications, Academic Press Inc., 1993.

28 G. Jiang, W. Huang, L. Li, X. Wang, F. Pang, Y. Zhang and H. Wang, Carbohydr. Polym., 2012, 87, 2012-2018.

29 N. A. Spaldin, Magnetic materials: fundamentals and applications, Cambridge University Press, 2010.

30 B. Frka-Petesic, J. Sugiyama, S. Kimura, H. Chanzy and G. Maret, Macromolecules, 2015, 48, 8844-8857.

31 A. Barhoumi Meddeb, I. Chae, A. Han, S. H. Kim and Z. Ounaies, Cellulose, 2020, 27, 7901-7910.

32 J. Pan, W. Hamad and S. K. Straus, Macromolecules, 2010, 43, 3851-3858.

33 L. Csoka, I. C. Hoeger, O. J. Rojas, I. Peszlen, J. J. Pawlak and P. N. Peralta, ACS Macro Lett., 2012, 1, 867-870.

34 J. A. Diaz, X. Wu, A. Martini, J. P. Youngblood and R. J. Moon, Biomacromolecules, 2013, 14, 2900-2908.

35 A. B. Reising, R. J. Moon and J. P. Youngblood, J. Sci. Technol. For. Prod. Processes, 2012, 2, 32-41.

36 J. Sugiyama, H. Chanzy and G. Maret, Macromolecules, 1992, 25, 4232-4234.

37 S. Elazzouzi-Hafraoui, Y. Nishiyama, J. L. Putaux, L. Heux, F. Dubreuil and C. Rochas, Biomacromolecules, 2008, 9, 57-65.

38 A. Nowogrodzki, Nature, 2018, 563, 24-26.

39 Y. Mao, M. Bleuel, Y. Lyu, X. Zhang, D. Henderson, H. Wang and R. M. Briber, Langmuir, 2018, 34, 8042-8051.

40 T. Pullawan, A. N. Wilkinson and S. J. Eichhorn, Biomacromolecules, 2012, 13, 2528-2536.

41 D. Li, Z. Liu, M. Al-Haik, M. Tehrani, F. Murray, R. Tannenbaum and H. Garmestani, Polym. Bull., 2010, 65, 635-642. 
42 D. H. Kim and Y. S. Song, Carbohydr. Polym., 2015, 126, 240-247.

43 K. J. De France, K. G. Yager, T. Hoare and E. D. Cranston, Langmuir, 2016, 32, 7564-7571.

44 H. C. Kim, J. W. Kim, L. Zhai and J. Kim, Cellulose, 2019, 26, 5821-5829.

45 H. Rashid, M. A. Mansoor, B. Haider, R. Nasir, S. B. Abd Hamid and A. Abdulrahman, Sep. Sci. Technol., 2020, 55, 1207-1215.

46 V. L. Lassalle, R. D. Zysler and M. L. Ferreira, Mater. Chem. Phys., 2011, 130, 624-634.

47 S. Y. H. Abdalkarim, Z. Ouyang, H. Y. Yu, Y. Li, C. Wang, R. A. M. Asad, Y. Lu and J. Yao, Carbohydr. Polym., 2021, 254, 117481.

48 M. Rashid, M. A. Gafur, M. K. Sharafat, H. Minami, M. A. J. Miah and H. Ahmad, Carbohydr. Polym., 2017, 170, 72-79.

49 M. H. Beyki, M. Bayat, S. Miri, F. Shemirani and H. Alijani, Ind. Eng. Chem. Res., 2014, 53, 14904-14912.

50 C. Wan and J. Li, ACS Sustainable Chem. Eng., 2015, 3, 2142-2152.

51 J. R. Correa, E. Bordallo, D. Canetti, V. León, L. C. OteroDíaz, C. Negro, A. Gómez and R. Sáez-Puche, Mater. Res. Bull., 2010, 45, 946-953.

52 M. Anbia and F. Rahimi, J. Appl. Polym. Sci., 2017, 134, 45361.

53 H. Y. Zhu, Y. Q. Fu, R. Jiang, J. H. Jiang, L. Xiao, G. M. Zeng, S. L. Zhao and Y. Wang, Chem. Eng. J., 2011, 173, 494-502.

54 X. Zhao, H. Li, A. Ding, G. Zhou, Y. Sun and D. Zhang, Mater. Lett., 2016, 163, 154-157.

55 H. Wu, H. Tian, S. Li, Y. Wang, Z. Ma, Z. Song and J. Wang, Cellulose, 2019, 27, 357-367.

56 X. Yu, S. Tong, M. Ge, J. Zuo, C. Cao and W. Song, J. Mater. Chem. A, 2013, 1, 959-965.

57 A. M. Donia, A. A. Atia and F. I. Abouzayed, Chem. Eng. J., 2012, 191, 22-30.

58 R. Xiong, Y. Wang, X. Zhang and C. Lu, RSC Adv., 2014, 4, 22632-22641.

59 A. S. M. Wittmar, Q. Fu and M. Ulbricht, ACS Sustainable Chem. Eng., 2017, 5, 9858-9868.

60 A. S. M. Wittmar, Q. Fu and M. Ulbricht, Cellulose, 2019, 26, 4563-4578.

61 S. Peng, J. Fan and J. Chang, Adv. Mater. Res., 2013, 634-638, 913-917.

62 M. L. Maxim, N. Sun, H. Wang, J. R. Sterner, A. Haque and R. D. Rogers, Nanomater. Energy, 2012, 1, 225-236.

63 X. Y. Wei, J. H. Li and J. C. Chen, Adv. Mater. Res., 2013, 634-638, 2077-2080.

64 S. Peng, H. C. Meng, L. Zhou and J. Chang, J. Nanosci. Nanotechnol., 2014, 14, 7010-7014.

65 S. Peng, H. Meng, Y. Ouyang and J. Chang, Ind. Eng. Chem. Res., 2014, 53, 2106-2113.

66 A. Ali, M. Z. Hira Zafar, I. ul Haq, A. R. Phull, J. S. Ali and A. Hussain, Nanotechnol., Sci. Appl., 2016, 9, 49.

67 W. Yang, H. Tian, J. Liao, Y. Wang, L. Liu, L. Zhang and A. Lu, Appl. Surf. Sci., 2020, 507, 145092.
68 N. Torkashvand and N. Sarlak, Eur. Polym. J., 2019, 118, 128-136.

69 S. Liu, J. Zhou and L. Zhang, Cellulose, 2011, 18, 663-673.

70 A. M. Tang and J. K. Song, Adv. Mater. Res., 2011, 239-242, 175-181.

71 W.-B. Wu, Y. Jing, M.-R. Gong, X.-F. Zhou and H.-Q. Dai, BioResources, 2011, 6, 3396-3409.

72 X. Pineda, G. C. Quintana, A. P. Herrera and J. H. Sánchez, Mater. Chem. Phys., 2021, 259, 122778.

73 F. Abujaber, F. J. Guzman Bernardo and R. C. Rodriguez Martin-Doimeadios, Talanta, 2019, 201, 266-270.

74 F. Abujaber, M. Zougagh, S. Jodeh, Á. Ríos, F. J. Guzmán Bernardo and R. C. Rodríguez Martín-Doimeadios, Microchem. J., 2018, 137, 490-495.

75 X. Yu, D. Kang, Y. Hu, S. Tong, M. Ge, C. Cao and W. Song, RSC Adv., 2014, 4, 31362-31369.

76 C. Wan and J. Li, Carbohydr. Polym., 2015, 134, 144-150.

77 R. T. Olsson, M. A. Azizi Samir, G. Salazar-Alvarez, L. Belova, V. Strom, L. A. Berglund, O. Ikkala, J. Nogues and U. W. Gedde, Nat. Nanotechnol., 2010, 5, 584-588.

78 T. Nypelö, C. Rodriguez-Abreu, J. Rivas, M. D. Dickey and O. J. Rojas, Cellulose, 2014, 21, 2557-2566.

79 C. Tian, S. Fu and L. A. Lucia, Cellulose, 2015, 22, 2571-2587.

80 Q. Chen, J. Zheng, Q. Yang, Z. Dang and L. Zhang, ACS Appl. Mater. Interfaces, 2019, 11, 15478-15488.

81 K. Gupta, J. Kaur, A. Kaushik and S. Singhal, Mater. Today, 2019, 14, 417-425.

82 A. Dhahri, H. Jaoua-Bahloul, M. H. V. Baouab, D. Luneau and E. Beyou, Polym. Eng. Sci., 2018, 58, 1630-1635.

83 C. Wan, Y. Jiao, X. Li, W. Tian, J. Li and Y. Wu, Nanoscale, 2020, 12, 3308-3316.

84 P. Tartaj, M. del Puerto Morales, S. VeintemillasVerdaguer, T. González-Carreño and C. J. Serna, J. Phys. D: Appl. Phys., 2003, 36, R182.

85 E. Lizundia, A. Maceiras, J. L. Vilas, P. Martins and S. Lanceros-Mendez, Carbohydr. Polym., 2017, 175, 425-432.

86 Y. Li, H. Zhu, H. Gu, H. Dai, Z. Fang, N. J. Weadock, Z. Guo and L. Hu, J. Mater. Chem. A, 2013, 1, 15278-15283.

87 S. Liu, D. Tao and L. Zhang, Powder Technol., 2012, 217, 502-509.

88 M. Rubacha and J. Zieba, Fibres Text. East. Eur., 2007, 15, 64 .

89 H. Fukuzumi, T. Saito, T. Iwata, Y. Kumamoto and A. Isogai, Biomacromolecules, 2008, 10, 162-165.

90 A. Walther, J. V. Timonen, I. Diez, A. Laukkanen and O. Ikkala, Adv. Mater., 2011, 23, 2924-2928.

91 R. Wu and C. Hu, Cellulose, 2021, 28, 1499-1511.

92 Y. Tang, Q. Zhang, L. Wang, P. W. Pan and G. Bai, Langmuir, 2010, 26, 11266-11271.

93 P. Prikryl, J. Lenfeld, D. Horak, M. Ticha and Z. Kucerova, Appl. Biochem. Biotechnol., 2012, 168, 295-305.

94 A. Shah, M. Kuddushi, K. Mondal, M. Jain and N. Malek, J. Mol. Liq., 2020, 320, 114290.

95 J. Duan, X. He and L. Zhang, Chem. Commun., 2015, 51, 338-341. 
96 J. Yan, D. Horak, J. Lenfeld, M. Hammond and M. KamaliMoghaddam, J. Biotechnol., 2013, 167, 235-240.

97 K. Du, X. Liu, S. Li, L. Qiao and H. Ai, ACS Sustainable Chem. Eng., 2018, 6, 11578-11586.

98 X. Luo, J. Zeng, S. Liu and L. Zhang, Bioresour. Technol., 2015, 194, 403-406.

99 L. E. Low, B. T. Tey, B. H. Ong, E. S. Chan and S. Y. Tang, Carbohydr. Polym., 2017, 155, 391-399.

100 W. Zhu, W. Ma, C. Li, J. Pan and X. Dai, Chem. Eng. J., 2015, 276, 249-260.

101 T. Nypelö, C. Rodriguez-Abreu, Y. V. Kolen'ko, J. Rivas and O. J. Rojas, ACS Appl. Mater. Interfaces, 2014, 6, 16851-16858.

102 Z. Liu, D. Li, H. Dai and H. Huang, J. Mol. Liq., 2017, 232, 449-456.

103 H. Zhang, Q. Luan, H. Tang, F. Huang, M. Zheng, Q. Deng, X. Xiang, C. Yang, J. Shi, C. Zheng and Q. Zhou, Cellulose, 2016, 24, 903-914.

104 Z. Liu, H. Wang, C. Liu, Y. Jiang, G. Yu, X. Mu and X. Wang, Chem. Commun., 2012, 48, 7350-7352.

105 Z. Liu, H. Wang, B. Li, C. Liu, Y. Jiang, G. Yu and X. Mu, J. Mater. Chem., 2012, 22, 15085-15091.

106 Y. Zhou, S. Fu, L. Zhang, H. Zhan and M. V. Levit, Carbohydr. Polym., 2014, 101, 75-82.

107 F. Lin, J. Zheng, W. Guo, Z. Zhu, Z. Wang, B. Dong, C. Lin, B. Huang and B. Lu, Cellulose, 2019, 26, 6861-6877.

108 J. Ren, Q. Dai, H. Zhong, X. Liu, L. Meng, X. Wang and F. Xin, Cellulose, 2018, 25, 4537-4549.

109 C. Qin, W. Yang, Y. Wang, L. Zhang and A. Lu, Cellulose, 2021, 28, 2353-2364.

110 M. Tatsumi, F. Kimura, T. Kimura, Y. Teramoto and Y. Nishio, Biomacromolecules, 2014, 15, 4579-4589.

111 L. Cao, Z. Cheng, M. Yan and Y. Chen, Chem. Eng. J., 2019, 363, 203-212.

112 M. Mashkour, M. Tajvidi, T. Kimura, F. Kimura and G. Ebrahimi, BioResources, 2011, 6, 4731-4738.

113 H. Yoshitake, K. Sugimura, Y. Teramoto and Y. Nishio, Polymer, 2016, 99, 147-156.

114 S. Galland, R. L. Andersson, M. Salajková, V. Ström, R. T. Olsson and L. A. Berglund, J. Mater. Chem. C, 2013, 1, 7963-7972.

115 H. Fukuzumi, T. Saito and A. Isogai, Carbohydr. Polym., 2013, 93, 172-177.

116 Y. Qing, R. Sabo, Y. Wu and Z. Cai, BioResources, 2012, 7, 3064-3075.

117 Q. Tarres, A. Deltell, F. X. Espinach, M. A. Pelach, M. Delgado-Aguilar and P. Mutje, Int. J. Biol. Macromol., 2017, 99, 29-36.

118 M. Zeng, A. Laromaine, W. Feng, P. A. Levkin and A. Roig, J. Mater. Chem. C, 2014, 2, 6312-6318.

119 S. Galland, R. L. Andersson, V. Ström, R. T. Olsson and L. A. Berglund, ACS Appl. Mater. Interfaces, 2014, 6, 20524-20534.

120 T. Hosoya, W. Sakamoto and T. Yogo, Mater. Lett., 2014, 137, 491-494.

121 K. K. Sadasivuni, D. Ponnamma, H.-U. Ko, H. C. Kim, L. Zhai and J. Kim, Sens. Actuators, B, 2016, 233, 633-638.
122 T. Chen, Q. Zhao, X. Meng, Y. Li, H. Peng, A. K. Whittaker and S. Zhu, ACS Nano, 2020, 14, 9440-9448.

123 M. Skwierczynska, M. Runowski, S. Goderski, J. Szczytko, J. Rybusinski, P. Kulpinski and S. Lis, ACS Omega, 2018, 3, 10383-10390.

124 M. Skwierczyńska, P. Woźny, M. Runowski, M. Perzanowski, P. Kulpiński and S. Lis, J. Alloys Compd., 2020, 829, 154456.

125 C. Wan, Y. Jiao, S. Wei, L. Zhang, Y. Wu and J. Li, Chem. Eng. J., 2019, 359, 459-475.

126 M. Giese, L. K. Blusch, M. Schlesinger, G. R. Meseck, W. Y. Hamad, M. Arjmand, U. Sundararaj and M. J. MacLachlan, Langmuir, 2016, 32, 9329-9334.

127 F. Abujaber, M. Jimenez-Moreno, F. J. Guzman Bernardo and R. C. Rodriguez Martin-Doimeadios, Mikrochim. Acta, 2019, 186, 400.

128 T. Ahamad, M. Naushad, Ruksana, A. N. Alhabarah and S. M. Alshehri, Int. J. Biol. Macromol., 2019, 132, 1031-1038.

129 Y. F. Wang, Y. G. Wang, X. K. Ouyang and L. Y. Yang, ACS Appl. Mater. Interfaces, 2017, 9, 1759-1769.

130 S. Cui, X. Wang, X. Zhang, W. Xia, X. Tang, B. Lin, Q. Wu, X. Zhang and X. Shen, Cellulose, 2017, 25, 735-751.

131 S. Daneshfozoun, M. A. Abdullah and B. Abdullah, Ind. Crops Prod., 2017, 105, 93-103.

132 X. Wang, S. Jiang, S. Cui, Y. Tang, Z. Pei and H. Duan, Cellulose, 2019, 26, 5051-5063.

133 A. M. Donia, A. M. Yousif, A. A. Atia and S. A. Labib, J. Dispersion Sci. Technol., 2014, 36, 898-907.

134 X. Luo, X. Lei, N. Cai, X. Xie, Y. Xue and F. Yu, ACS Sustainable Chem. Eng., 2016, 4, 3960-3969.

135 X. Sun, L. Yang, Q. Li, J. Zhao, X. Li, X. Wang and H. Liu, Chem. Eng. J., 2014, 241, 175-183.

136 J. Lu, R. N. Jin, C. Liu, Y. F. Wang and X. K. Ouyang, Int. J. Biol. Macromol., 2016, 93, 547-556.

137 X. Luo, X. Lei, X. Xie, B. Yu, N. Cai and F. Yu, Carbohydr. Polym., 2016, 151, 640-648.

138 S. Hokkanen, E. Repo, S. Lou and M. Sillanpää, Chem. Eng. J., 2015, 260, 886-894.

139 H. Dai, Y. Huang, Y. Zhang, H. Zhang and H. Huang, Cellulose, 2019, 26, 3825-3844.

140 H. Shi, W. Li, L. Zhong and C. Xu, Ind. Eng. Chem. Res., 2014, 53, 1108-1118.

141 R. Samadder, N. Akter, A. C. Roy, M. M. Uddin, M. J. Hossen and M. S. Azam, RSC Adv., 2020, 10, 11945-11956.

142 S. Peng, Y. Liu, Z. Xue, W. Yin, X. Liang, M. Li and J. Chang, Cellulose, 2017, 24, 4793-4806.

143 K. Srasri, M. Thongroj, P. Chaijiraaree, S. Thiangtham, H. Manuspiya, P. Pisitsak and S. Ummartyotin, Int. J. Biol. Macromol., 2018, 119, 662-668.

144 B. Li, Q. Zhang, Y. Pan, Y. Li, Z. Huang, M. Li and H. Xiao, Int. J. Biol. Macromol., 2020, 163, 309-316.

145 J. Sun, L. Cui, Y. Gao, Y. He, H. Liu and Z. Huang, Carbohydr. Polym., 2021, 251, 117004.

146 S. L. Cao, X. H. Li, W. Y. Lou and M. H. Zong, J. Mater. Chem. B, 2014, 2, 5522-5530.

147 E. J. Cho, S. Jung, H. J. Kim, Y. G. Lee, K. C. Nam, H. J. Lee and H. J. Bae, Chem. Commun., 2012, 48, 886-888. 
148 K. A. Mahmoud, E. Lam, S. Hrapovic and J. H. Luong, ACS Appl. Mater. Interfaces, 2013, 5, 4978-4985.

149 H. Suo, L. Xu, Y. Xue, X. Qiu, H. Huang and Y. Hu, Carbohydr. Polym., 2020, 234, 115914.

150 H. H. Je, S. Noh, S.-G. Hong, Y. Ju, J. Kim and D. S. Hwang, Chem. Eng. J., 2017, 323, 425-433.

151 J. Zhang, X. Feng, J. Wang, G. Fang, J. Liu and S. Wang, Analyst, 2020, 145, 3407-3413.

152 M. Rahimi, S. Shojaei, K. D. Safa, Z. Ghasemi, R. Salehi, B. Yousefi and V. Shafiei-Irannejad, New J. Chem., 2017, 41, 2160-2168.

153 C. Wan and J. Li, ACS Sustainable Chem. Eng., 2015, 3, 2142-2152.

154 M. H. Mohamed Noor, N. Ngadi, I. Mohammed Inuwa, L. A. Opotu and M. G. Mohd Nawawi, J. Environ. Chem. Eng., 2020, 8, 104014.

155 S. Periyasamy, V. Gopalakannan and N. Viswanathan, Carbohydr. Polym., 2017, 174, 352-359.

156 A. H. Nordin, S. Wong, N. Ngadi, M. Mohammad Zainol, N. A. F. Abd Latif and W. Nabgan, J. Environ. Chem. Eng., 2021, 9, 104639.

157 E. S. Mirjavadi, R. M. A. Tehrani and A. Khadir, Environ. Sci. Pollut. Res., 2019, 26, 33478-33493.

158 Z. Zhang, H. Li, J. Li, X. Li, Z. Wang, X. Liu and L. Zhang, Chem. Phys. Lett., 2019, 731, 136573.

159 S. F. Chin, A. N. Binti Romainor and S. C. Pang, Mater. Lett., 2014, 115, 241-243.

160 Z. Xu, X. Jiang, H. Zhou and J. Li, Cellulose, 2017, 25, 1217-1227.

161 H. Peng, H. Wang, J. Wu, G. Meng, Y. Wang, Y. Shi, Z. Liu and X. Guo, Ind. Eng. Chem. Res., 2016, 55, 832-838.

162 H. Gu, X. Zhou, S. Lyu, D. Pan, M. Dong, S. Wu, T. Ding, X. Wei, I. Seok, S. Wei and Z. Guo, J. Colloid Interface Sci., 2020, 560, 849-856.

163 X. He, T. Chen, T. Jiang, C. Wang, Y. Luan, P. Liu and Z. Liu, Carbohydr. Polym., 2021, 260, 117790.

164 L. E. Low, L. T. Tan, B. H. Goh, B. T. Tey, B. H. Ong and S. Y. Tang, Int. J. Biol. Macromol., 2019, 127, 76-84.
165 Y. Li, Y. Feng, J. Jing and F. Yang, BioResources, 2019, 14, 3615-3629.

166 N. Wang, Y. F. Wang, A. M. Omer and X. K. Ouyang, Anal. Bioanal. Chem., 2017, 409, 6643-6653.

167 H. Huang, X. Wang, H. Ge and M. Xu, ACS Sustainable Chem. Eng., 2016, 4, 3334-3343.

168 Z. H. Hu, Y. F. Wang, A. M. Omer and X. K. Ouyang, Int. J. Biol. Macromol., 2018, 107, 453-462.

169 N. Wang, X.-K. Ouyang, L.-Y. Yang and A. M. Omer, ACS Sustainable Chem. Eng., 2017, 5, 10447-10458.

170 H. Lu, L. Zhang, B. Wang, Y. Long, M. Zhang, J. Ma, A. Khan, S. P. Chowdhury, X. Zhou and Y. Ni, Cellulose, 2019, 26, 4909-4920.

171 T. Ghosh, Y. Teramoto and V. Katiyar, J. Agric. Food Chem., 2019, 67, 4289-4299.

172 M. A. Hobisch, S. Zabler, S. M. Bardet, A. Zankel, T. Nypelö, R. Eckhart, W. Bauer and S. Spirk, Carbohydr. Polym., 2021, 254, 117406.

173 S. Liu, Q. Yan, D. Tao, T. Yu and X. Liu, Carbohydr. Polym., 2012, 89, 551-557.

174 P. Dhar, A. Kumar and V. Katiyar, ACS Appl. Mater. Interfaces, 2016, 8, 18393-18409.

175 Y. C. Yee, R. Hashim, A. R. Mohd Yahya and Y. Bustami, Sensors, 2019, 19, 2511.

176 N. M. Aguilar, F. Arteaga-Cardona, M. E. de Anda Reyes, J. J. Gervacio-Arciniega and U. Salazar-Kuri, Mater. Chem. Phys., 2019, 238, 121921.

177 F. Zhang, R. Wang, C. Zhen and B. Li, J. Mol. Catal. B: Enzym., 2016, 134, 164-171.

178 J. Guo, I. Filpponen, L. S. Johansson, P. Mohammadi, M. Latikka, M. B. Linder, R. H. Ras and O. J. Rojas, Biomacromolecules, 2017, 18, 898-905.

179 Y. Li, H. Zhu, C. Zhang, M. Cheng and H. He, Cellulose, 2018, 25, 4757-4769.

180 S. M. A. S. Keshk, A. A. El-Zahhar, A. M. S. Youssef and S. Bondock, Mater. Res. Express, 2019, 6, 085310.

181 S. M. A. S. Keshk, A. A. El-Zahhar, A. G. Al-Sehemi, A. Irfan and S. Bondock, Mater. Res. Express, 2018, 6, 025312. 